\title{
Echocardiographic Findings in Labradors with Dilated Cardiomyopathy
}

\author{
G. R. Athira ${ }^{1 *}$, P. Thirunavukkarasu ${ }^{2}$, S. Kavitha ${ }^{3}$, K. Vijayarani ${ }^{4}$, \\ D. Chandrasekaran ${ }^{5}$ and A. Serma Saravana Pandian ${ }^{6}$ \\ Tamilnadu Veterinary and Animal Sciences University, \\ Madras Veterinary College, Chennai-600 007, India \\ *Corresponding author
}

A B S T R A C T

\begin{tabular}{l} 
Ke y w o r d s \\
Dilated \\
Cardiomyopathy, \\
Echocardiography, \\
Labradors \\
\hline Article Info \\
\hline $\begin{array}{l}\text { Accepted: } \\
\text { 25 February } 2020 \\
\text { Available Online: } \\
\text { 10 March } 2020\end{array}$ \\
\hline
\end{tabular}

Idiopathic dilated cardiomyopathy is the common form of dilated cardiomyopathy. The fantasy of keeping Labradors as pet is increasing day by day and the population of this breed was little higher when compared to other breeds presented to Madras Veterinary College Teaching Hospital (MVC), Chennai. The incidence of dilated cardiomyopathy in this breed is more than other breeds. The confirmation of this disorder is done by echocardiography which showed increased internal diameter of left ventricle during systole and diastole, increased left atrium and aorta ratio, reduced fractional shortening and increased end point septal separation.

\section{Introduction}

Cardiovascular disorder is the second commonest disease causing premature deaths in canines. Idiopathic dilated cardiomyopathy is the most common form of dilated cardiomyopathy which is commonly seen in giant and large breeds. Various etiological factors are responsible for dilated cardiomyopathies in humans.

The clinical signs of the disease are non specific and may be misdiagnosed as respiratory tract diseases. Hence the confirmation of this disorder requires a series of diagnostic modalities to rule out other possible disease which shows similar clinical signs.

The commonly used diagnostic modalities include radiography, electrocardiography and confirmation of the disorder is done by using echocardiography. Echocardiographic evaluation is the most sensitive method of confirming myocardial dysfunction. The diagnosis of DCM is based on the identification of myocardial dysfunction with active exclusion of other acquired or congenital cardiac disease (McEwan et al., 2003). 


\section{Materials and Methods}

Ten apparently healthy Labrador retrievers brought for routine health checkup formed the source of control group (Group-I). Group II consists of DCM affected Labrador which were selected randomly. A total of twenty four DCM affected Labradors were selected in Group II. The study was carried out during the year 2017-2018.Echocardiographic was carried out as suggested by (Boon 1998) using ALOKA SSD 3500 ultrasound system with micro convex cardiac probe of $3.0-6.0 \mathrm{MHz}$ to obtain the two dimensional, M-mode and color flow Doppler echocardiographic images of heart.

\section{Results and Discussion}

This study showed significant increase in the left atrium and aorta ratio of the affected animals (Thirunavukkrasu, 2016). Increase in the ratio indicates left ventricular dilatation (figure 1a). The present study showed increase in left atrium dimension and nonsignificant change in the aortic dimension (Lombard, 1984). The measurement of aorta is to see the abnormalities in the stroke volume. The increase in the LA/AO ratio increases from the normal value if there is a left atrial enlargement which in turn indicates a left ventricular dilatation.

There is a significant increase in the values such as left ventricular internal diameter during diastole (LVIDd), left ventricular internal diameter during systole (LVIDs), reduced fractional shortening (FS) (figure 1b)and increase EPSS (figure 1c) in dilated cardiomyopathy affected animals when compared to the healthy animals (Vollmar,1999). The mean value of FS\% in affected animals was $18.85 \pm 1.01$ which was categorised as DCM with moderate systolic failure (Kittleson, 1998).

Table.1 Echocardiographic Findings in Normal and DCM Labradors

\begin{tabular}{|l|l|l|l|l|l|}
\hline Parameters & $\begin{array}{l}\text { Group I } \\
(\mathbf{n = 1 0})\end{array}$ & $\begin{array}{l}\text { Group II } \\
(\mathbf{n = 2 4})\end{array}$ & t-Test & p-Value & Result \\
\hline $\begin{array}{l}\text { LVIDd(cm) } \\
(\mathbf{c m})\end{array}$ & $3.59 \pm 0.19$ & $5.66 \pm 0.13$ & 8.66 & 0.0000 & $* *$ \\
\hline LVIDs (cm) & $2.20 \pm 0.15$ & $4.61 \pm 0.13$ & 10.11 & 0.0000 & $* *$ \\
\hline EDV (ml) & $49.88 \pm 7.15$ & $185.68 \pm 13.58$ & 6.25 & 0.0000 & $* *$ \\
\hline ESV(ml) & $11.99 \pm 2.10$ & $104.11 \pm 9.40$ & 6.24 & 0.0000 & $* *$ \\
\hline SV(ml) & $37.89 \pm 5.45$ & $81.58 \pm 6.45$ & 4.10 & 0.0003 & $* *$ \\
\hline EF\% & $76.86 \pm 1.99$ & $44.77 \pm 2.50$ & 7.81 & 0.0000 & $* *$ \\
\hline FS\% & $39.03 \pm 1.766$ & $18.85 \pm 1.01$ & 10.41 & 0.0000 & $* *$ \\
\hline LA(cm) & $2.84 \pm 0.12$ & $4.09 \pm 0.12$ & 6.05 & 0.0000 & $* *$ \\
\hline AO(cm) & $2.31 \pm 0.17$ & $2.24 \pm 0.05$ & 0.52 & 0.6080 & NS \\
\hline LA/AO & $1.20 \pm 0.03$ & $1.86 \pm 0.04$ & 9.55 & 0.0000 & $* *$ \\
\hline EPSS(cm) & $0.69 \pm 0.07$ & $2.04 \pm 0.10$ & 8.09 & 0.0000 & $* *$ \\
\hline
\end{tabular}




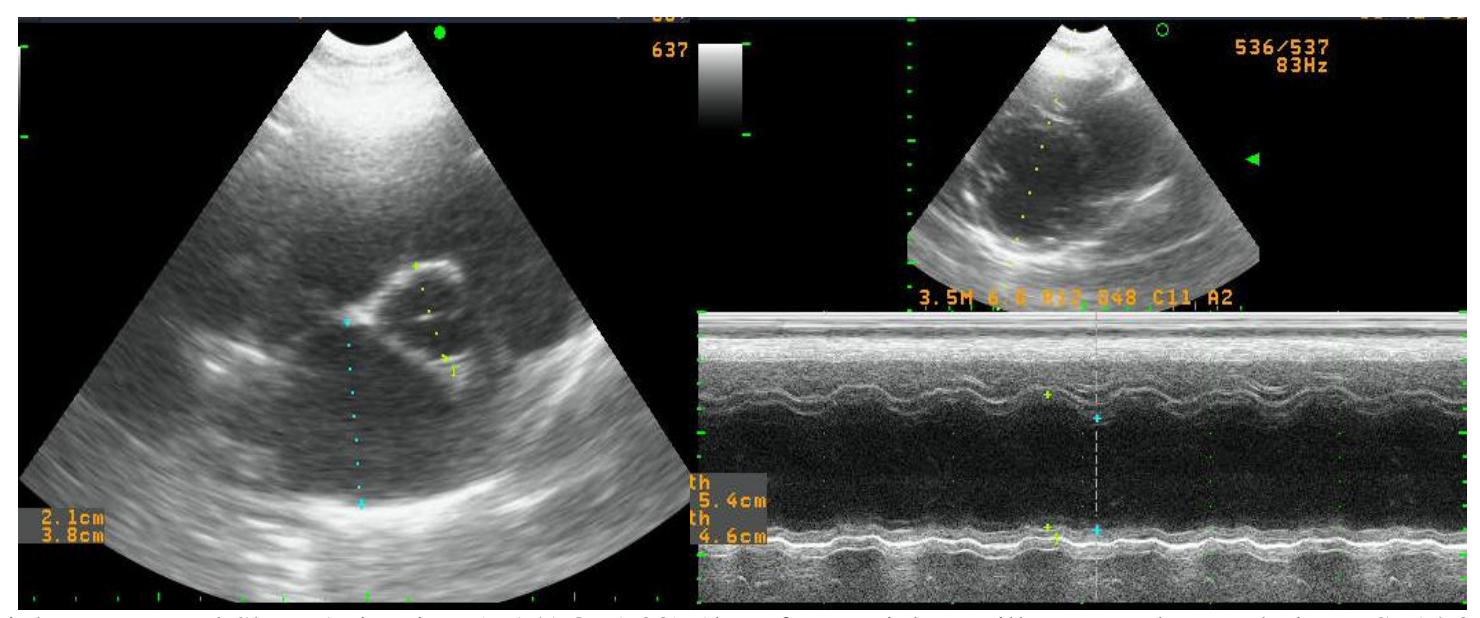

Right Parasternal Short Axis View (LA/AO=1.80) 1b Left Ventricle Papillary Muscle Level view FS=14.8\% Figure.1a and 1b Echocardiographic findings in Labradors with DCM

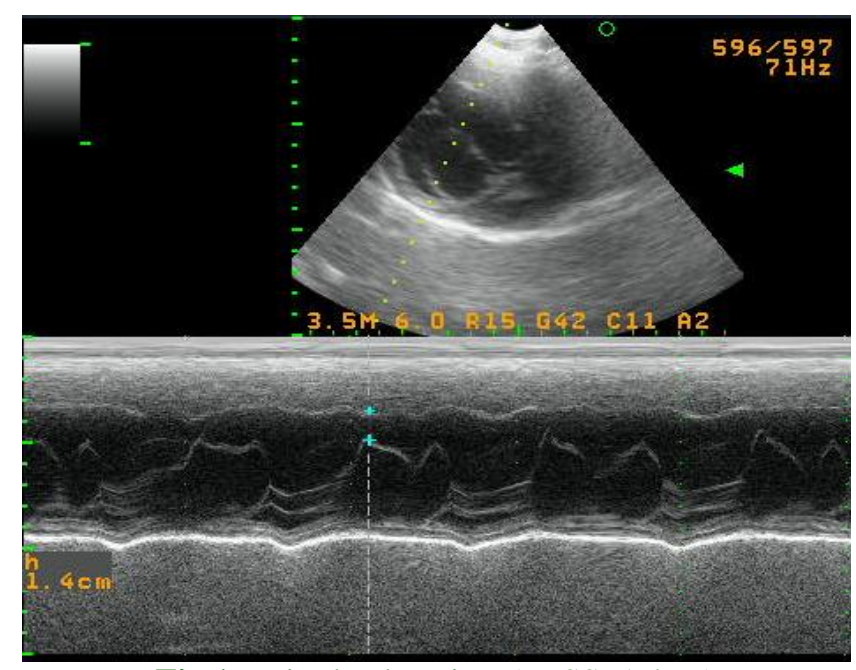

Fig.1c Mitral valve view (EPSS=1.4cm)

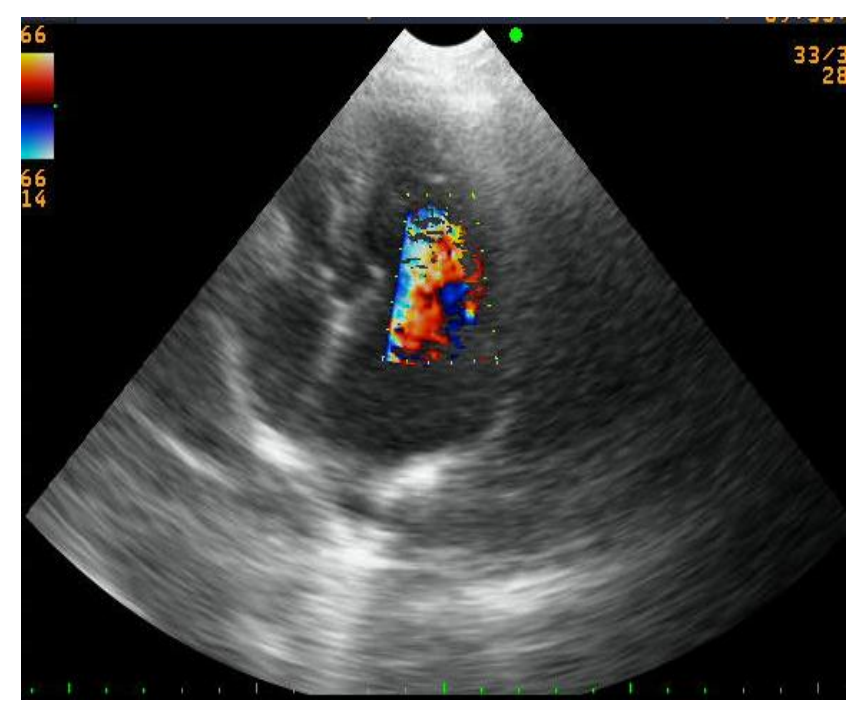

Fig.1d Color flow Echocardiography

Left apical four chamber view- mitral regurgitation 
Dilated cardiomyopathy is a systolic failure of heart hence the parameters of systolic function was altered in the present study. Larger diameter of left ventricular in systole indicates poorer contractility.

There was a significant reduction in the fractional shortening in the present study which was in agreement with several authors Calvert et al., (1982); Monnet et al., (1995); Borgarelli et al., (2006) and Jeyaraja et al., (2015).

This study showed highly significant increase in EPSS values in DCM dogs and was concurred with several authors Calvert et al., (1982); Calvert and Brown (1986); Monnet et al., (1995); (McEwan, 1999) and (Vollmar,1999).EPSS were a most sensitive and specific criteria for the recognition of early cardiomyopathy (Calvert and Brown, 1986).

The increase in EPSS is due to the increase in the dimension of the left ventricle. EPSS is a valuable parameter if M-mode instead of Simpson measurements is used (Holler and Wess, 2014). E-point to septal separation was one of the consistent (Normal value $7.7 \mathrm{~mm}$ ) and popular mitral valve measurements (Boon, 2011).

In DCM presence of high end diastolic left ventricular pressures reduced the flow from left atrium to left ventricle due to reduced ventricular compliance and consequently flow out of left ventricle were also reduced. EPSS had a negative correlation with ejection fraction in the absence of aortic and mitral insufficiencies.

\section{Color flow echocardiography}

Mitral insufficiency in DCM affected dogs which occurs secondary to the dilatation of the chambers and improper closure of tricuspid and mitral valves was the cause of murmur in the present cases (Kienle and Thomas, 1995). The present study showed mitral insufficiency in two of the total twenty four affected animals (figure 1d).

\section{References}

Boon, J.A. 1998. Manual of Veterinary Echocardiograhy. Blackwell Publishing.Professional, Ames, Lowa, USA.

Boon, J.A. 2011. Veterinary Echocardiography. 2nd Ed. WileyBlackwell, Ames, Iowa, USA.

Borgarelli, M., Santilli, R.A., Chiavegato, D., D’Agnolo, G, Zanatta, R, Mannelli, A and Tarducci, A. 2006. Prognostic indicators for dogs with dilated cardiomyopathy. Journal of Veterinary Internal Medicine., 20: 104-110.

Calvert, C., and Brown, J. 1986. Use of Mmode echocardiography in the diagnosis of congestive cardiomyopathy in DobermanPinschers. Journal of American Veterinary Medical Association., 3: 293-297.

Calvert, C.A., W.L.Chapman and R.L.Toal. 1982. Congestive cardiomyopathy in Doberman pinscher dogs. Journal of American Veterinary Medical Association., 181: 598-602.

diagnostic ultrasound. W.B.Saunders, Philadelphia. pp.206-208.

echocardiographic measurements. In: T.G.Nyland, J.S.Mattoon, eds. Veterinary

Jeyaraja, k., A.Arun, Hamsa Yamini, P.S.L.Sesh and A.P.Nambi.2015. Diagnostic Evaluation of Dilated Cardiomyopathy in Labrador Retrievers. International Journal of Advanced Research.,3: 628 - 655 .

Kienle, R.D. and W.P.Thomas. 1995. Echocardiography, recommended methods for 
Kittleson, M.D. 1998. Primary myocardial disease leading to chronic myocardial failure. Small animal cardiovascular medicine.St.Louis: Mosby; p. 319-346.

Lombard, C.W. 1984. Echocardiographic and clinical signs of dilated cardiomypathy. Journal of Molecular and Cellular Cardiology., 25:59-70.

McEwan,

J.D.

1999.

Echocardiographic/Doppler criteria of normality, the findings of cardiac disease and the genetics of familial dilated cardiomyopathy in Newfoundlands. PhDThesis. The University of Edinburgh. 108-116.

McEwan, J.D., M.Borgarelli, A.Tidholm, A.C.Vollmar and J.Häggstrom,2003. Proposed Guidelines for the Diagnosis of Canine Idiopathic Dilated Cardiomyopathy. Journal of Veterinary
Cardiology., 5:7-19.

Monnet, E., C.E.Orton, M.Salman and J.Boon. 1995. Idiopathic dilated cardiomyopathy in dogs: Survival and prognostic indicators. Journal of Veterinary Internal Medicine., 9:12-17.

P.J. Holler and G. Wess.2014. Sphericity Index and E-Point-to-Septal-Separation (EPSS) to Diagnose Dilated Cardiomyopathy in Doberman Pinschers. Journal of veterinary internal medicine., 28:123-129.

Thirunavukkarassu,P.2016. Ph.D Thesis submitted to Tamilnadu Veterinary and Animal Sciences University.

Vollmar, A.C. 1999. Use of echocardiography in the diagnosis of dilated cardiomyopathy in Irish Wolfhounds. Journal of American Animal Hospital Association., 35:279-283.

\section{How to cite this article:}

Athira. G. R., P. Thirunavukkarasu, S. Kavitha, K. Vijayarani, D. Chandrasekaran and Serma Saravana Pandian. A. 2020. Echocardiographic Findings in Labradors with Dilated Cardiomyopathy. Int.J.Curr.Microbiol.App.Sci. 9(03): 3072-3076. doi: https://doi.org/10.20546/ijcmas.2020.903.352 